\title{
Discussion on Integrated Utilization Technology of Rural Breeding Waste
}

\author{
Xiang-yang Huang ${ }^{a}$, Ren Liu ${ }^{b}$ \\ School of Urban Construction, Yangtze University, Jingzhou 434023, China \\ aemail:mikecheng@126.com, bemail:liurenshihaoren@163.com
}

\begin{abstract}
Keywords: Ecological farm, Breeding contaminant, Reclamation of wastes, Circular agriculture. Abstract: Breeding contaminant is one of the important pollution sources of the rural ecological environment. It is an effective way to control environmental pollution that the solid waste and wastewater generated in captive breeding is used as resource. Propose a circulation agriculture model with "planting-breeding-biogas-fertilizer" combined organically. This model was applied in a farm in Jinniu town, Daye city, Hubei province. Through the follow-up survey and data analysis of the production on the farm, the results showed that the economic benefits not only was significant but also solved the pollution of the breeding contaminant completely. It actually accomplished "zero emissions". It proved that this model was suitable for small and medium-scale farms. It could provide reference for development pattern of ecological agriculture development in China.
\end{abstract}

\section{Introduction}

Livestock and poultry breeding industry is one of the important ways to develop rural economy, and the livestock pollution is an important part of environmental pollution [1]. The waste mainly includes sewage, livestock manure and malodorous gas etc [2]. If it is improperly disposed, it will direct or indirect impact on water, air, soil, environmental sanitation and human health. The instant development and discharge capacity sustained increase of scale of livestock and poultry breeding industry had become an significant source of pollution. Majority of farms have no corresponding measures of pollution control because that the problem of the sitting and environmental pollution is not well considered, which makes the breeding waste become one of the important pollution source of people living areas, water source protection areas, rivers, lakes and air [3 5].

Extensive research of livestock pollutants for the prevention, treatment and comprehensive utilization had been done at home and abroad [6 8]. The total quantity control of water pollutants in the twelfth national "five" plan put agricultural source pollution into it for the first time, and how to reduce the poultry pollution, improve the environment, save energy and adopt the strategy of sustainable development of livestock have become an urgent problem. Therefore, exploring economic and applicable livestock pollution treatment technology is one of the effective ways to solve the rural environment pollution, which has a very important significance to protect the rural environment, realize the livestock waste of free-pollution disposal and its resource utilization, ensure sustainable development of livestock and poultry breeding industry and guide the modern agricultural rational and circular development.

\section{Material and Methods}

A planting and breeding farm in Jinniu town, Daye city, Hubei province is a typical ecological agricultural demonstration base. It was built in 2010.The farm breeds 105 sows, 1200 piglets, 20 goats and 100 ducks, and plants a total of 22 acres of crops such as rice, corn, canola, wheat, watermelons, vegetables, etc. The base also has a over 8000 square meters reservoir area and 3 fish ponds. The farms produces about 3.2 tons manure and 5 to $10 \mathrm{~m}^{3}$ breeding wastewater per day. Previously a part of livestock manure is used to fertilize crops and another part of it directly stacked or landfilled, which causes great pollution on soil and air environment after a long time. While the breeding wastewater is discharged into the reservoir after septic tanks, in the long run it will seriously 
pollute the water quality of the reservoir, further may pose a threat to the security of drinking water for rural residents nearby.

To solve the problems, we combined the national energy-saving emission reduction policies and put forward a "planting-breeding-biogas-fertilizer" combined organically circulation agriculture pattern. The specific methods of operation was: manure generation from livestock and poultry breeding (It is mainly pig manure.) fermented to produce biogas, and its biogas slurry processed into fertilizer for crops; a part of breeding wastewater added into the biogas digester and fermented with manure, and the rest of it entered into the artificial wetland after separation, the wetlands planted aquatic as of edible forage fodder for fish, and the treated water was discharged into the fish pond; while strows and corncobs, etc. produced from crops were processed into feed to feed pigs and fish. This pattern was shown in Figure 1.The farm began to use this mode of operation from March 2012. we studied the production operation of the different seasons on the farm.

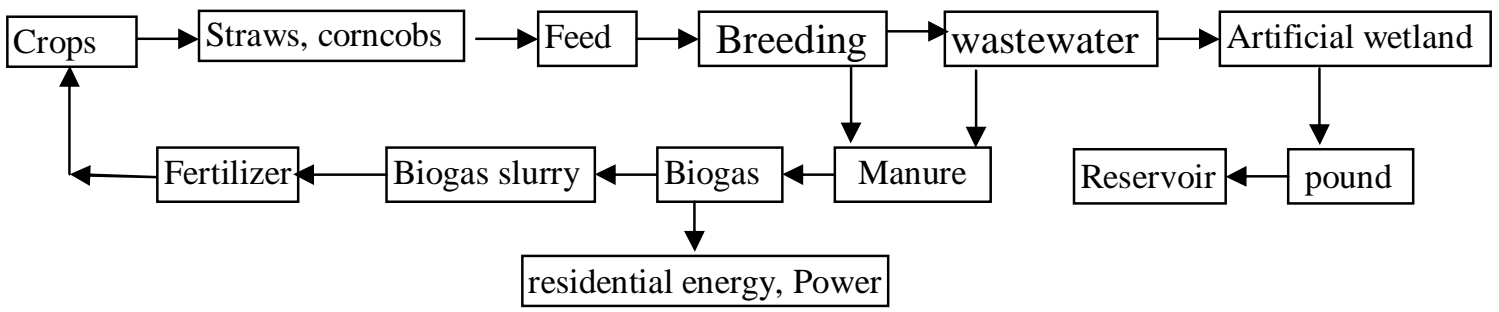

Figure.1 An ecological agriculture model of "planting-breeding-biogas-fertilizer" combined organically

Analysis Method: with GC9800 gas chromatograph analysis of biogas composition; with UV spectrophotometric analysis the total nitrogen, total phosphorus; indene column after trione derivative method for the analysis amino acids. Inductively coupled plasma atomic emission spectroscopy (ICP-OES, USA ThermoFisher company) analysis the metal ions and trace elements.

\section{Results and analysis}

\section{Production and utilization of biogas from breeding manure}

The biogas digester used the cylinder type and hydraulic biogas digester, the pool depth was $2.2 \mathrm{~m}$, the diameter was $3.6 \mathrm{~m}$, and the total volume of it was about $22 \mathrm{~m}^{3}$. It used mesophilic digestion to produce biogas. In order to improve gas production in winter, the wastewater was heated properly before entering the biogas digester mixed with manure. The production of biogas is $13 \mathrm{~m}^{3}$, and a part of it is used as residential energy for themself, the other is used of electricity generation, which can basically meet electric consumption on lighting for the whole farm.

\section{The comprehensive utilization mode of biogas slurry and residues}

Biogas fermentation is a process of biogas energy production and composting. In this process, nutrient element for crop growth basically like nitrogen, phosphorus and potassium etc. was basically retained, so the biogas slurry is a good source of organic fertilizer. At the same time, biogas slurry keeps rich in amino acid, vitamin B, a variety of hydrolase, some auxin and a substance or factor on the inhibition of plant diseases and insect pests, so it also can be used to feed fish, pigs and cattle, and prevent some diseases and insect pests of crops, and has wide prospects for comprehensive utilization. Biogas residues is the semi solid material left in the bottom of the biogas digester after the biogas fermentation, it contains rich in organic matter, humic acid, crude protein, nitrogen, phosphorus, potassium and trace elements, etc., and it is a kind of slow and speed united high quality organic fertilizer and aquaculture bait [9]. We mixed biogas slurry, residues and crops straw such as crushed wheat and rape, etc., and processed them into organic compound fertilizer. A part of this fertilizer was 
used for crops fertilizer of the base, and most of the remaining were sold to the nearby villagers. Only this one item could income $12000 y u a n$ per year. The fertilizer could make the vegetables grow faster and the chlorophyll content higher, and increase yield $20 \%$ than common compound fertilizers on crops, and its benefit was obvious. In addition, we found that the application of the organic manure could control plant diseases and insect pests and improve plant resistance. This was mainly because the biogas fermentation material contained beneficial substances like hormones and antibiotics, etc. which improved plant resistance after the anaerobic fermentation.

\section{The comprehensive utilization mode of crops straw}

The traditional method mixes crops straw and corncobs and processes them into feed, but the crude fiber content of this feed is high, and the content of amino acid and protein is lack. It is not suitable for pigs, only suitable for cattle, sheep and other ruminant. But it is completely different if we crush the rice straw, wheat straw, corn stalk, corncobs, peanut vine and sweet potato vine, mix them with biogas slurry, and process them into feed. It can produce high nutrition and high performance biological feed, and this feed can replace part of the grain feed to feed pigs, chickens, ducks, fish and sheep, etc. Research showed that using this biological to feed the pigs could not only promote the growth of pigs, shorten the fattening period, improve the feed conversion rate, reduce feed meat ratio, but also could increase the pig resistance and prevent some pig disease. The test found that this feed not only contained amino acid promoted the growth of pigs, but also contained copper, iron, and other trace elements. we also used this feed to fish and duck, and the results was successful, especially solving the problem of shortage of fish grass. We found that the feed was not only nutritious, but also could speed up the reproduction of plankton in pond and reservoir, reduce the oxygen consumption, improve water quality, make the water keep dark brown and easy to absorb heat, increase water temperature, and make the pond remain neutral, all of these positive factors could promote the better growth of fish. Feed produced in this way can more than meet the needs of the base, and most of them can sell, and the resulting net income is over 20,000 yuan per year.

\section{The breeding wastewater treatment and comprehensive utilization technology}

The livestock wastewater has the following characteristics: large drainage volume, centralization of water, high strength of hydraulic shock loading and high concentration of organic matter. Wastewater often is accompanied by sterilized water, heavy metals, residues of veterinary drugs and various kinds of zoonotic pathogens and other pollutants [10 12]. Untreated breeding wastewater contains a lot of organic contaminants and nutrients such as $\mathrm{N}$ and $\mathrm{P}$. It is an important pollution source, and also the nutrient elements required for agricultural production. If the breeding wastewater can be purified by the methods of physical, chemical and biological, and combined the treated water with the agricultural water-saving irrigation, it not only can realize the efficient use or emission standards of breeding wastewater, but also can achieve the purpose of turning waste into treasure and comprehensive utilization. This has great significance to alleviate the water shortage in agriculture, realize the area zoology environmental protection and improve the living environment.

To reduce the harm of breeding wastewater to the environment, we established a hoggery wastewater treatment and its utilization system. The system strengthened the pre-treatment process for the fresh manure by processing the solid-liquid separation, removing sediment and using pretreatment. $30 \%$ of the wastewater entered into the biogas digester, mixed with manure and digested, and the rest $70 \%$ of it was sent to artificial wetland for processing. Plants grown in artificial wetland was fish grass. Plenty of microbial formed stable biofilm in fillers surface of artificial wetland and roots of fish grass, and organic matter was removed by the adsorption and assimilation, alienation effect of the biofilm. Meanwhile, roots of fish grass in the wetland beds formed aerobic, anoxic and anaerobic conditions circle in the surrounding by transmission of oxygen, which could not only ensure $\mathrm{N}, \mathrm{P}$, etc. in breeding wastewater be directly absorbed by fish grass and microbial, but also could ensure $\mathrm{N}$, $\mathrm{P}$, etc. be removed from the wastewater by nitrification, denitrification and excess accumulation effect of microbial on P. After more than one year's operation, the system could achieve low cost and high efficient completion of the breeding wastewater treatment and resource utilization, and the treated water quality index could reach $\mathrm{COD}_{\mathrm{Cr}} \leq 200 \mathrm{mg} / \mathrm{L}, \mathrm{TP} \leq 2 \mathrm{mg} / \mathrm{L}, \mathrm{NH}_{3}-\mathrm{N} \leq$ 
$20 \mathrm{mg} / \mathrm{L}, \mathrm{TN} \leq 80 \mathrm{mg} / \mathrm{L}$. Investment of wetland needs just 12,000 yuan and it is all investment. so it is not a burden to the business, and the fish grass grown in wetland can partially solve the issues of fish foodstuff, which has the Equivalent economic efficiency and good environment benefit.

\section{Conclusions}

The author put forward a circulation agriculture model with"planting-breeding-biogas-fertilizer" through the integration research of the breeding pollution treatment technology on a typical rural breeding farm in Hubei. It is a new approach to carry out comprehensive utilization of agricultural cultivation of solid waste and wastewater. This approach follows the "small biological cycle" rules, takes planting as the premise, centers around livestock and poultry breeding, combines planting, breeding, biogas, aquaculture and some other industries. It can utilize and develop the natural resources in multiple levels, which not only can enhance the economic benefit, but also can improve the ecological environment. It achieved "zero emissions" of pollutants and had very high economic benefit. It centered around livestock and poultry breeding, combined planting, breeding, biogas, feed and aquatic, and formed a comprehensive circulation agriculture pattern.Research shows that the mode is suitable for small and medium sized rural planting and breeding bases, which can provide reference for development model of ecological agriculture in china.

\section{Acknowledgements}

This work was financially supported by the Hubei Natural Science Foundation (2014CFB334), Innovation Program of Hubei Education Commission (Q20141309).

\section{References}

[1] Geng Lin, Dan Dezhong, Ma Zelong. Analysis of environmental economics on the resource utilization of livestock waster water. China water resources.2003, Vol(11): 4-7

[2] Yang Lin, Zhou Shenfu, Pei Xin. The countermeasures of mountain pig scale breeding waste treatment. Heilongjiang Animal Science and Veterinary Medicine. 2011,Vol (2): 29-31

[3] Pang Yan, Zhang Wenyang, WuYan . The effective ways to solve the point source pollution of non-intensive livestock production waste. Animal Husbandry \& Veterinary Medicine, 2010, vol 42( 6): $97-99$

[4] Shi yujuan . Considerations on Becoming Resources of agricultural Discard in China .Journal of Jilin Agricultural Sciences.2012,vol( 6): 75-78

[5] Lin Cong, Duan La . Biogas technology in the large scale application of piggery wastewater treatment. Swine Industry Science. 2013,vol 10: 42-43

[6] Heath, Jeffrey H. Integrated waste management breeds success. Journal of New England Water Environment Association, 2008,vol 42,(1):26-29

[7] Marcinkowski, T.A. . Utilization of electrohydrodynamic cavitation in primary sludge conditioning. Chemical and Biochemical Engineering Quarterly, 2010,vol 24(3): 377-382

[8] Banerjee, Soumyajit . Household disposables as breeding habitats of dengue vectors: Linking wastes and public health. Waste Management,2013, vol 33(1): 233-239

[9] Zhang Jun, Wang Aidong, Liu Jian . Study on "planting-breeding-biogas" of the circular agriculture mode. Ningxia Journal of Agriculture and Forestry Science and Technology,2013, vol.54(4): 84-88.

[10] Liu Yuze, Wei Yanwen, Yan Zhiyong . The New Treatment of High-concentration Livestock and Poultry Breeding Wastewater and Regulation Operation. Acta Ecologiae Animalis Domastici, 2009,vol 30(3): 82-85

[11] Castillo, S . Study of a compact bioreactor for the in-line treatment of dairy wastewaters: case of effluents produced on breeding farms. Desalination, v 214, n 1-3, p 49-61, August 15, 2007

[12] Lishtvan, I.I. Using copper ions for disinfection of wastewaters from stock-breeding complexes. Journal of Water Chemistry and Technology, v 28, n 3, p 50-54, 2006 